IOS Press

\title{
Erratum
}

\section{Erratum to: Report on the 4th Ottawa International Conference on Neuromuscular Disease and Biology - September 5-7, 2017, Ottawa, Canada}

Jodi Warman Chardon, Bernard J. Jasmin, Rashmi Kothary and Robin J. Parks

Pre-press 22 November 2021

[Journal of Neuromuscular Diseases, 5(4) (2018), 539-552, 10.3233/JND-180353]

https://content.iospress.com/articles/journal-of-neuromuscular-diseases/jnd180353

When this article was first published the first author's first name and last name were incorrectly indexed as "JW Chardon". This has been corrected to "J. Warman-Chardon" in the XML files of the revised online version of the article (DOI: 10.3233/JND-180353). 